\title{
Contamination Control in a Portable-Materials With Photochemical Process
}

\author{
Bruno Pereira de Oliveira ${ }^{1}$, Kate Cristina Blanco ${ }^{1}$, Vanderlei Salvador Bagnato ${ }^{1}$ \\ ${ }^{1}$ São Carlos Institute of Physics, University of São Paulo, PO Box 369, 13560-970, São Carlos, SP, Brazil \\ Correspondence: Bruno Pereira de Oliveira, São Carlos Institute of Physics, University of São Paulo, PO Box 369, \\ 13560-970, São Carlos, SP, Brazil. E-mail: pereirabrunno1 @ gmail.com
}

Received: May 15, 2019 Accepted: July 21, 2019 Online Published: July 24, 2019

doi:10.5539/ijc.v11n2p86 URL: https://doi.org/10.5539/ijc.v11n2p86

\begin{abstract}
Contamination control area refers to the control / eliminated of the activities of microorganisms present in the materials or process. This technique to eliminated is major importance in this study are those that cause food spoilage and are infectious. The principal areas of interest in this study are health, aerospace and food industry because the materials utilized in the process charging the contamination; thus, to control these microorganisms, moist heat and chemicals are used. However, technological development has led to a problem with some portable-materials, as these techniques are not suitable in specific cases in which there may be material damage and health safety problems. To address these problems, the present research identified a new constructive experimental device that has a triple deck (UV, Ozone, and UV-Ozone). This configuration can sterilize material with photochemical process cannot be damaged. After this protocol was generated, flat plate materials were contaminated with $E$. coli and 3 different configuration protocols were applied. The results show a microbial reduction of approximately $99.999 \%$ after an exposure of $30-40$ min with ozone/UV, 30 min with UV-only, and 20 min with ozone. This device has the ability to sterilize the materials.
\end{abstract}

Keywords: optical, decontamination, device, engineering, materials, dental

\section{Introduction}

Contamination control area refers to the control microorganisms present in the materials and process. This technique to eliminated is major importance in the dental offices, pharmaceutical industries, chemical laboratories, food industry and aerospace, because the materials utilized in the process charging the contamination (principal microorganism). These biological agents can transmit infectious various types of the diseases. Traditional decontamination of materials is performed by autoclaving with moist heat or ethylene. High temperatures and pressures are applied that can denature proteins from microorganisms, disrupting the replication of microorganisms. This process is indicated for heat stable materials or devices (materials that do not change physical-chemical characteristics when having a temperature variation) (Gayán et al.2014; Atlas et al., 1995; Friedberg et al., 2005).

Decontamination of thermosensitive materials involves chemical solutions. Sterilization of materials and devices by moist heat for the optimal time oxidizes biological structures of microorganism, and the protocols used are indicated by the World Health Organization (WHO) or the Food and Drug Administration (FDA) and require devices (autoclave) or other substances (Block, 2001; Guzel-Seydim,2004). However, scientific methodologies for contamination control that can protect human health and the environment in an economically beneficial way have been described. In 2002, the use of chemical substances to solve environmental problems was described for medical-dental instruments. The environmental problems and the industrial evolution of materials highlights the need to create new protocols for efficient microbiological control in medical materials.

This study describes the technological development has led to a problem a with some portable-materials, as these techniques are not in specific cases in which there may be material damage and health safety problems. This configuration can sterilize material with photochemical process, a device was developed and used in a triple platform for sterilization: UV, Ozone, UV-Ozone; the operation of these systems was demonstrated [6]. The capacity to decontaminate some portable-materials within the same device is a challenge in autoclaves. Some materials do not support heat and vapor while others cannot be in contact with ozone. Therefore, a 3-fold device is a platform with many capabilities. 


\section{Material and Methods}

\subsection{Manufacture Device}

The external structure of the device is an Autoclave Vitale 21 L (Bio-Art, São Carlos, São Paulo, Brazil), composed of aluminum. The quartz windows and moldings were sealed with O-rings to support high and low pressure.

The ozone generator inserted in the prototype was an Enaly /OZ-3ON (Enaly, Hong Kong, China) with an output of 100-200 mg/h. Ozone was integrated as needed into a 3-way solenoid valve (Thermoval, Cravinhos, São Paulo Brazil) to control the gas flow in the tank.

A UV lamp was used with a radiated power of 200-280 nm (UVC) and 0.9 W (OSRAM, São Paulo, São Paulo, Brazil), and the control process was performed with a programmable controller (Dakol, São Paulo, São Paulo Brazil).

\subsection{Characterization}

The light intensity in the prototype was controlled by an optical fiber connected to a spectrometer (USB $2000+$ UV-vis ocular optics) with a spectral range of 200-850 nm and an integration time of 1-65 ms (Fig. 1).

Figure 1: Schematic of the point of measurement of the intensity of UV light in the tank; A-) the red point is the location of collection, and the black arrows indicate the directions of Higher (H), Right (R), Left (L), or Below (B); B-) lateral view indicating the collection point, first in front of the tank (1), second in the middle of the tank (2), and third to the bottom of the pond. C-) Window design of the shell for the UV lamp; D-) prototype design in the Inventor software.
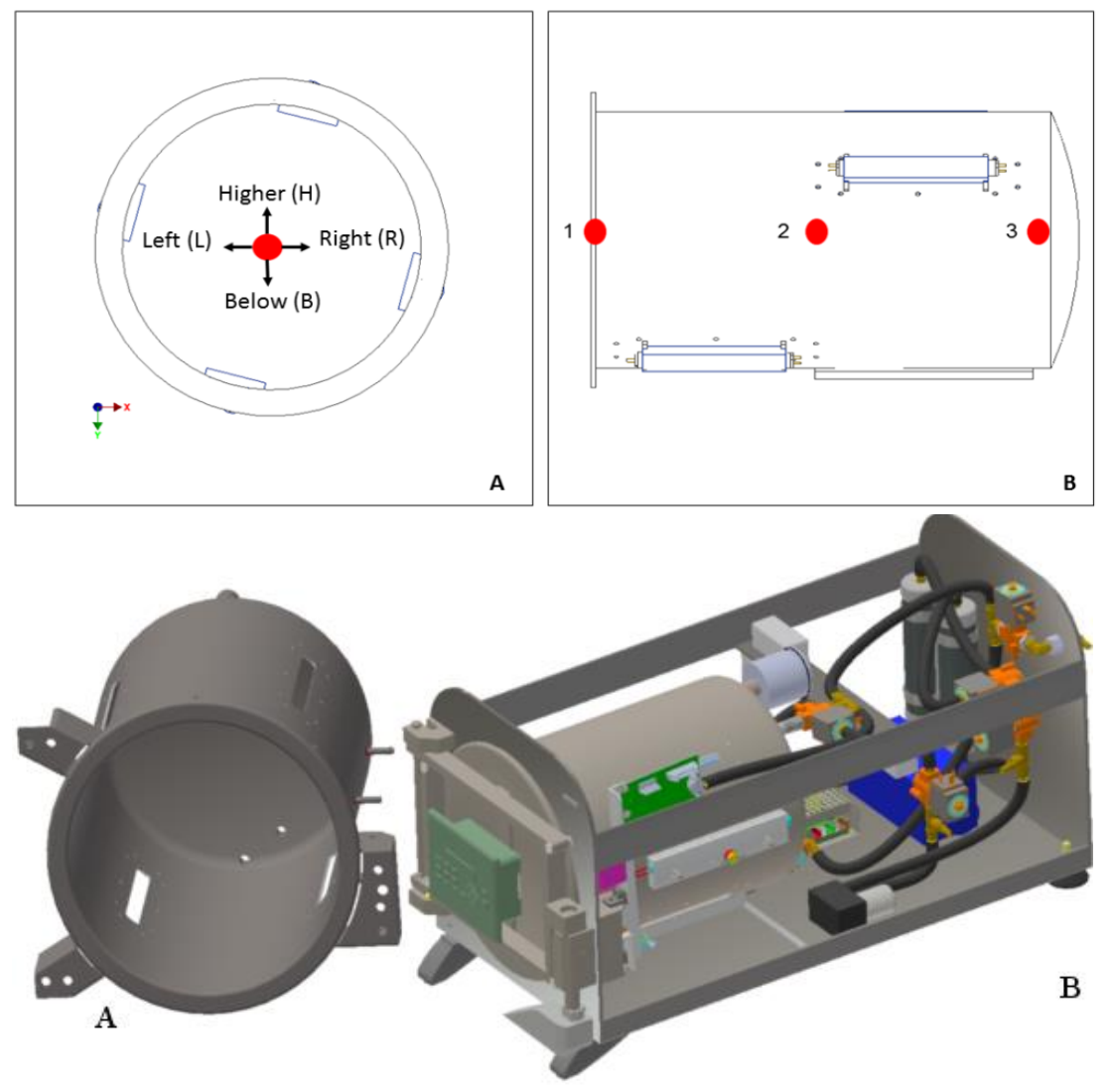

Figure 1. Schematic of the point of measurement of the intensity of UV light in the tank

The distribution of UV light in the autoclave was determined at the central point, which is indicated with a red dot. The black arrows indicate directions of $(\mathrm{A})$ higher than $(\mathrm{H})$ a two-sided point on the right tank $(\mathrm{R})$, one point on the left tank (L) and another below point (B).

There are three red dots in part B of Fig. 1: point one is the front of the autoclave, point two is the middle of the autoclave, and point three is the bottom of the autoclave.

UV intensity data collection was performed three times in each direction (black arrow) and along the three-point lines (red dot). 


\subsection{Microbiological Sterilization}

Microbial inactivation tests were performed with E. coli ATCC 25922, a member of the culture collection of the Biophotonics Laboratory of the São Carlos Institute of Physics (SP, Brazil) from the American Type Culture Collection.

E. coli $(10 \mu \mathrm{L})$ in a suspension of $10^{-9}(\mathrm{CFU} / \mathrm{mL})$ was inoculated in quartz plates. The experiments were performed under the following conditions: ozone, ozone $+\mathrm{UV}$, and UV. Aliquots $(100 \mu \mathrm{L})$ were collected at time intervals and diluted to $10^{-1}$ to $10^{-6}$ in PBS; then, colony-forming units (CFU) were determined.

\section{Results and Discussion}

The mechanical device used in this research was built in the optical laboratory of the University of São Paulo and has intellectual protection from the National Institute of Intellectual Property (NIIP) with registration number BR2020160165941. The design is shown in Fig. 1- C. Fig. 1-D shows four UV lamps surrounding the outer frame. A detailed description of the device and its $\mathrm{UV} / \mathrm{O}_{3}$ properties is described as follows: the mechanical design was modeled in a program for basic aspects, such as flow of ozone in the system using a 3-way solenoid to control and direct the catalysis or generation of ozone. The system operates with air present in an autoclave at room temperature without increasing the pressure in the device. The prototype includes selector valves, an ozone generator, UV lamps and electrical systems without a closed flow catalyst. The device was manufactured with a metallic structure, and components were inserted as a catalysis system. A programmable logic controller (PLC) to control the process was used in this prototype. To simulate the light distribution on the tank, a flat plate with an optimal absorbance was inserted, across the longitudinal axis (Fig. 2 - A).
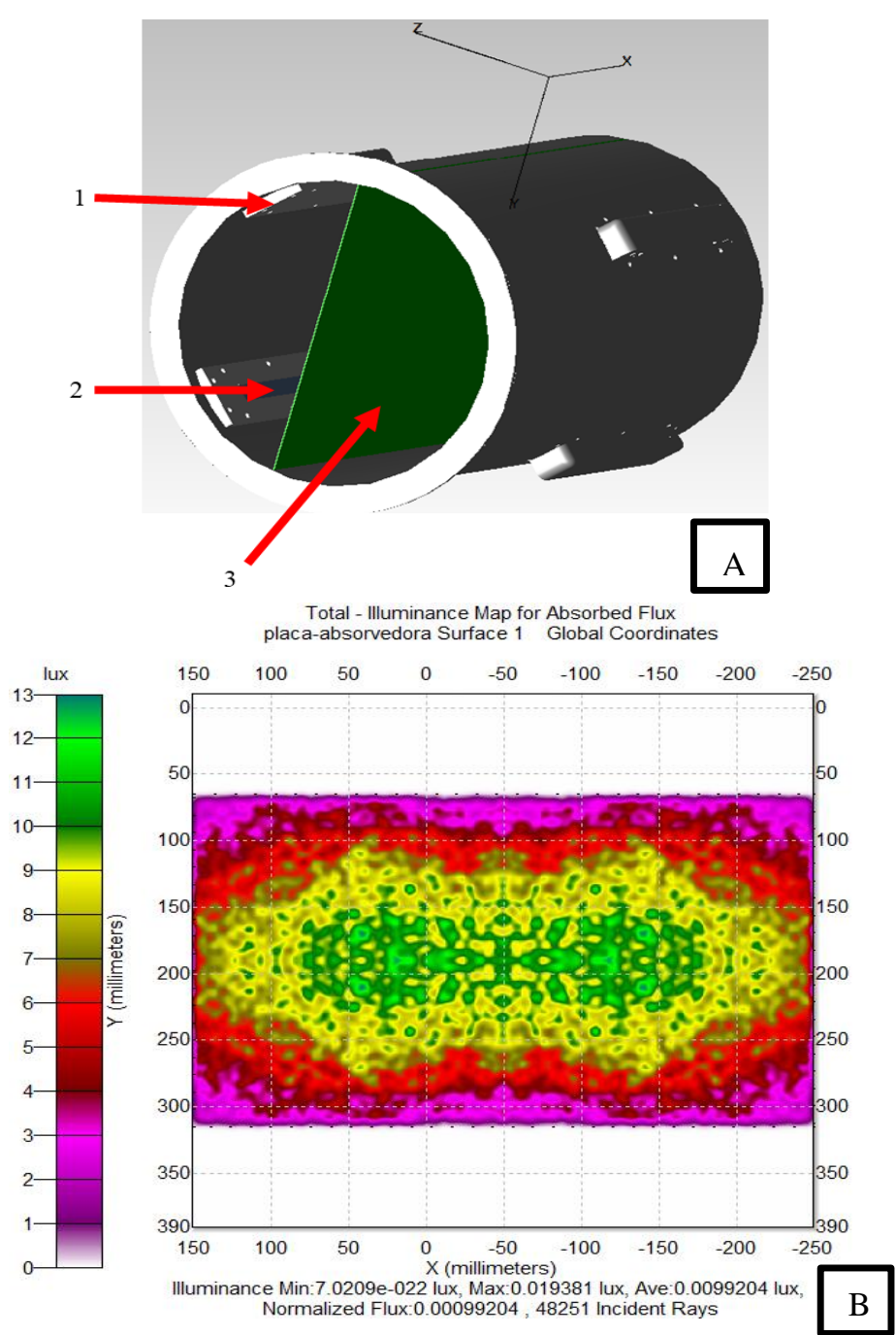

Figure 2. Position of the plate for analysis of the light distribution on the autoclave tank 
Fig. 2: A-) Position of the plate for analysis of the light distribution on the autoclave tank; 1-) the part that protects the lamp and is fixed in four locations; 2-) quartz that passes the UV wavelength; 3-) the plate for analyzing the light distribution. B-) The light distribution of the flat plate for analyzing the area with UV.

The results of the distribution are shown in Fig. 2 -B, and the distribution shows UV present in homogenous areas and UV absent in parts without light. This aspect is important for contamination control. As shown in fig. 2, there was a uniform light distribution in the apparatus. The purple region of the illuminance map represents the minimum intensity, and the green region represents the maximum intensity. In the central part, the maximum intensity was observed because of the distribution of the four lamps positioned at the front and the two lamps at the back. This configuration produces a homogeneous distribution. The light intensity was quantified with an energy meter. Energy delivery was measured at a range between 0.09 and $0.15 \mathrm{~mW} / \mathrm{cm}^{2}$. In the middle part of the tank, the intensity variation was between 0.44 and $0.84 \mathrm{~mW} / \mathrm{cm}^{2}$, and the light intensity of point 1 was in the range of 0.17 to $0.99 \mathrm{~mW} / \mathrm{cm}^{2}$. Table 1 shows the minimum dose of UV light needed for the elimination of some microorganisms.

Table 1. UV dose for the elimination of different microorganisms [1]

\begin{tabular}{|c|c|c|c|}
\hline Microorganism & UV dose $\left(\mathrm{mJ} / \mathrm{cm}^{2}\right)$ & References & \\
\hline E. coli $\mathrm{O} 25: \mathrm{K} 98: \mathrm{NM}$ & 5 & \multirow{5}{*}{$\begin{array}{l}\text { Gayán; Condón; } \\
\text { (2013) }\end{array}$} & \multirow{5}{*}{ Álvarez } \\
\hline Spores & 14.2 & & \\
\hline Acanthamoeba ssp. & 47.6 & & \\
\hline $\begin{array}{l}\text { Acanthamoeba Castellanii ATCC } \\
30234\end{array}$ & 60 & & \\
\hline $\begin{array}{l}\text { Micrococcus radiodurans ATCC } \\
13939\end{array}$ & 198.6 & & \\
\hline
\end{tabular}

The exposure time of UV was approximately $30 \mathrm{~min}$, and the light dose was calculated for the minimum and maximum intensities on the device (Table 2).

Table 2. Calculation of the dose at different points on the device with 30 minutes of exposure time

\begin{tabular}{ll}
\hline Intensity measured $\left(\mathbf{m W} / \mathbf{c m}^{2}\right)$ & Dose in $\mathbf{3 0} \mathbf{~} \operatorname{~in~}\left(\mathbf{~} \mathbf{J} / \mathbf{c m}^{2}\right)$ \\
\hline 0.09 & 160 \\
\hline 0.99 & 1782 \\
\hline
\end{tabular}

Table 2 shows the light distribution in the tank with the minimal exposure doses in the microorganisms. The results of the microbial death tests were analyzed according to colony forming units using ozone, cycles of UV, and ozone / UV. The sterilization results after the UV protocol are shown in fig. 3. 

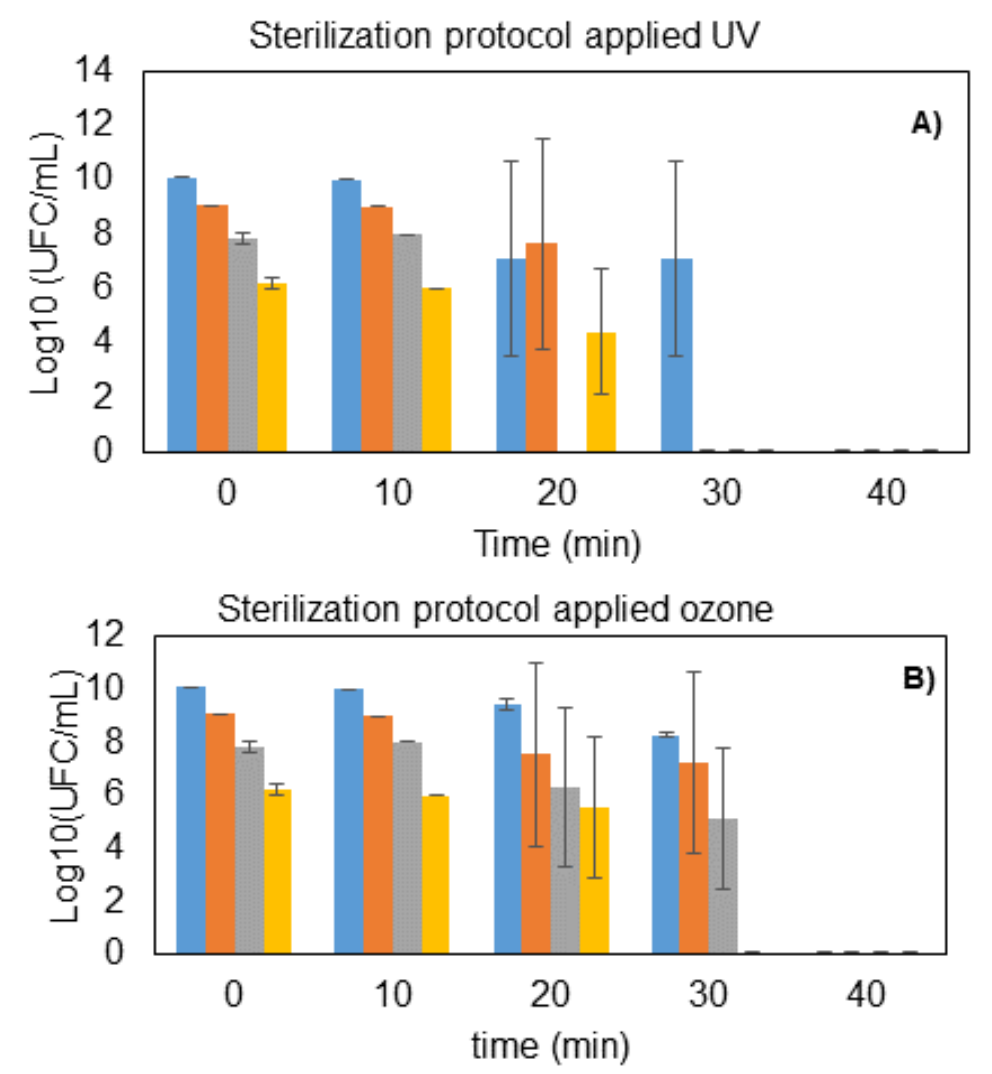

Sterilization protocol onjugate applied ozone

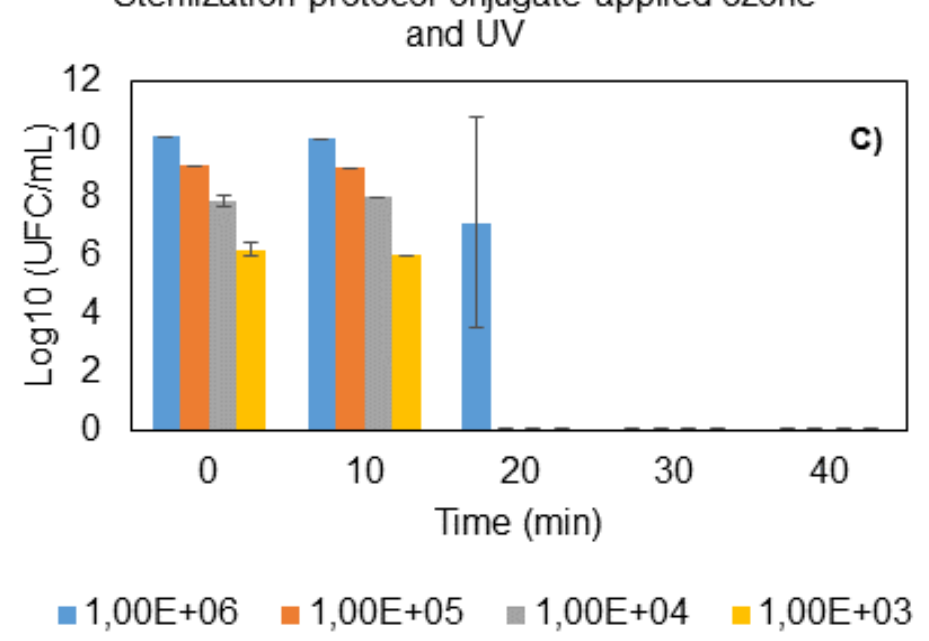

Figure 3. The results of the microbial death tests were analyzed according to colony forming units using ozone, cycles of UV, and ozone / UV. The sterilization results after the UV protocol

Fig. 3: A-) Results of sterilization cycles and the evaluated capacity of UV during the autoclave process using different initial concentrations of microorganism; B-) ozone application of the protocol for 40 minutes with 4 distinct initial concentrations of $10^{10}, 10^{9}, 10^{8}$ and $10^{6}$ colony-forming units per $\mathrm{mL}(\mathrm{CFU} / \mathrm{mL})$; C-) combined application of UV and ozone for sterilization for 40 minutes with 4 distinct initial concentrations of $10^{10}, 10^{9}, 10^{8}$ and $10^{6}$ colony-forming units per $\mathrm{mL}(\mathrm{CFU} / \mathrm{mL})$.

Figure 3 shows the bacterial reduction with the increasing process time. The use of UV results in sterilization times of 30 and 40 minutes with 4 distinct initial concentrations of $10^{10}, 10^{9}, 10^{8}$ and $10^{6}$ colony-forming unit per $\mathrm{mL}(\mathrm{CFU} / \mathrm{mL})$.

Fig. 3-Bs show the results following the ozone protocol and the different kinetics of the microorganisms. An antimicrobial mechanism with ozone gas occurs because of the oxidation of sulfhydryl groups, amino acids of the enzymes, and small peptides. Ozone $\left(\mathrm{O}_{3}\right)$ attacks unsaturated lipids, causing a break of cellular bonds (Guzel-Seydim et 
al., 2004). Another reported mechanism is the oxidation of the polyunsaturated fats presents in microorganisms, but this process does not have a specific oxidation site (Solomons, 2006). Dysfunction is generated by the attack, not a directed action, on the semipermeable membrane. Consequently, oxidation of ribonucleic acids occurs in the core or cytoplasm. The cellular wall ruptures, resulting in the diffusion of molecules within the cell and interference in cellular activities (Junqueira, 1998). Oxidation of the basic components of biological systems interferes with the energy level as enzymes and enzyme substrates are inactivated when cells are exposed to gases (Aguiar, 2006).

In gram-negative bacteria, gaseous ozone acts on lipoproteins and polysaccharides. These components and the cell are destroyed, which increases ozone permeability. E. coli has a high resistance to gaseous ozone because it has a double lipid layer (Tortora, 2009). As shown in fig. 5-A, microorganisms in contact with gaseous ozone are degraded, and the cell membranes of gram-negative microorganisms are modified.
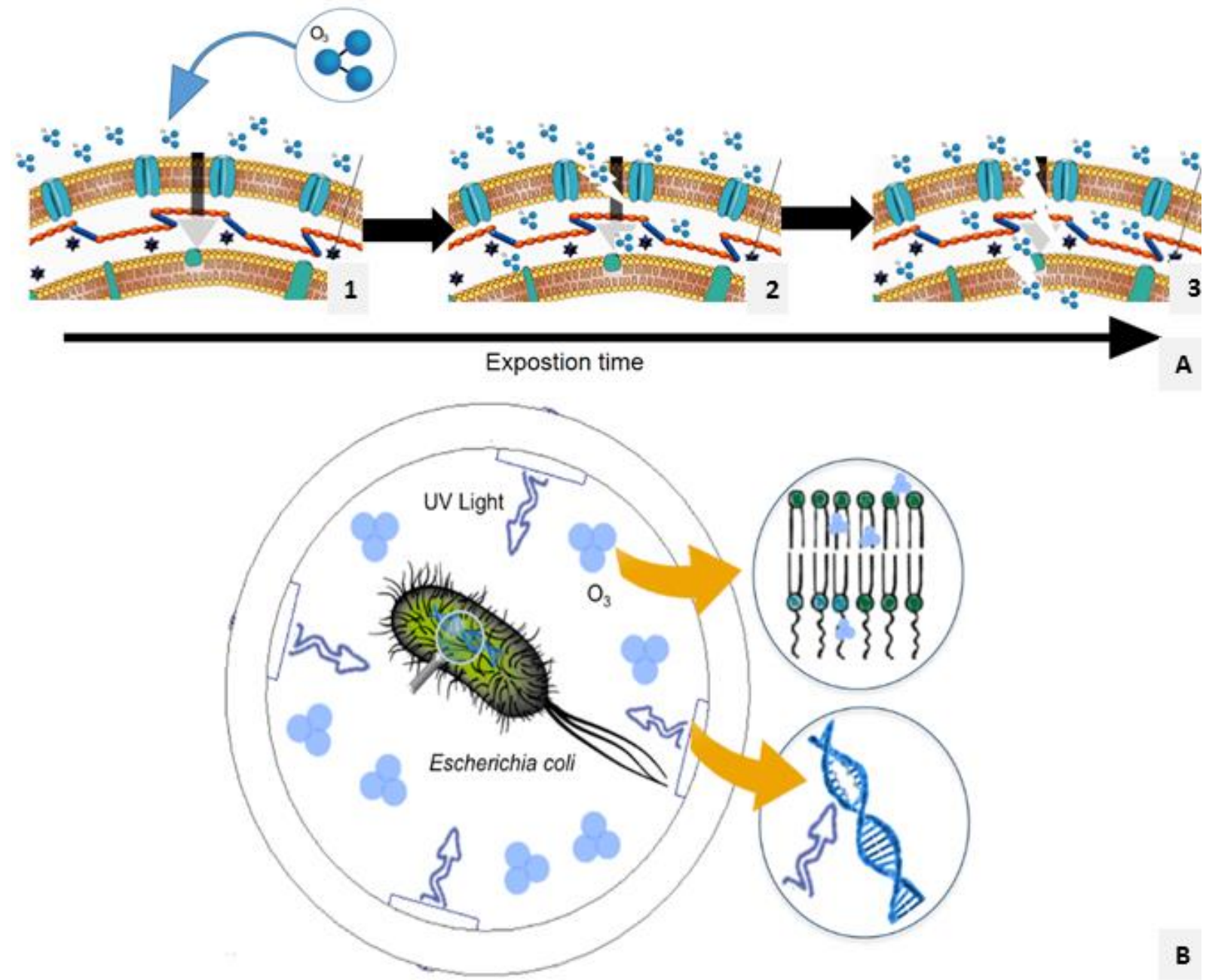

Figure 4. A-) Schematic of the mechanisms of action of ozone in the cellular membrane of a microorganism; the evolution time and perfusion of molecules into the cell from the oxidation process; B-) schematic of the UV and ozone attack in a microorganism when placed in a multifunctional autoclave 


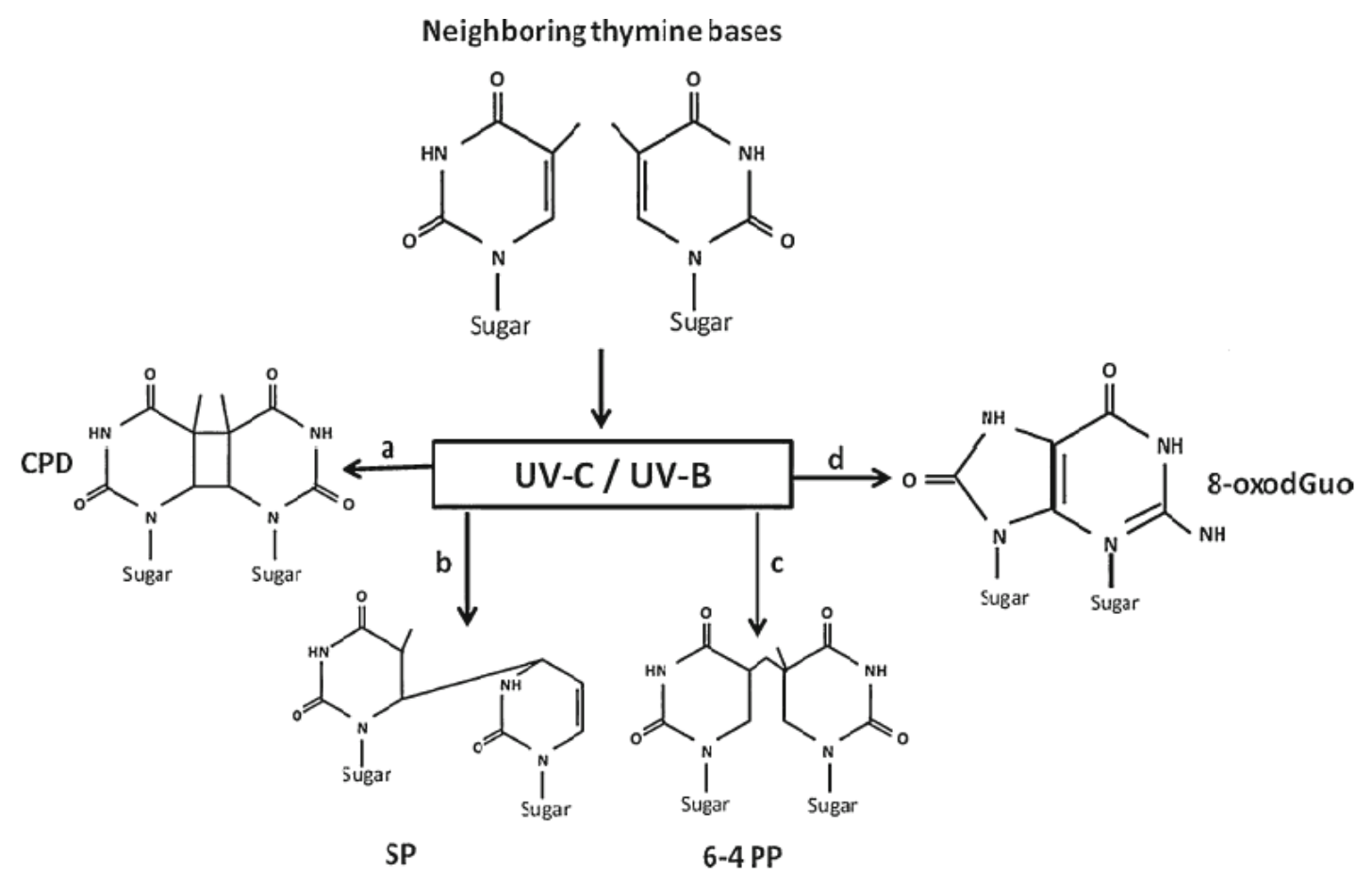

Figure 5. Damage caused by UV- C and UV-B in primary DNA: Cyclobutan pyrimidine dimer (CPD); (a) spore photoproduct (SP); (b) pyrimidine 6-4 pyrimidone photoproduct (6-4PP); (c) 8-oxo-7,8-dihydro-2'-deoxyguanosine; and (d) 8-oxodGuo [7].

Reportedly, UVC (200 - 280) irradiation can damage nucleic acids present in organisms because DNA absorbs energy when delivered in microorganisms. Pyrimidine molecules contain nitrogenized bases, and when photons are present, two main excited states exist, ${ }^{1 *}$ or ${ }^{1} *$, resulting in subsequent pyrimidine dimer formation [2]. However, microorganisms have defense mechanisms when there are mutations in the base structure, leading to an immediate recovery of photoproducts. Chemical compounds damage a DNA strand, (Figure), and when the rate of regeneration is slower than the rate of damage, DNA cannot be transcribed or replicated, leading to the death of the microorganism. (Gayán et al., 2014; Friedberg et al., 2005; Block, 2001).

Reduction of the time needed for sterilization of biological materials is needed. A time of $20 \mathrm{~min}$ was needed to eliminate a low concentration of microorganisms, and at a higher concentration, there was a decrease of approximately $3 \log _{10}(\mathrm{CFU} / \mathrm{mL})$ with a large offset between samples. After 30 and $40 \mathrm{~min}$, there were no microorganisms detected during testing. UV damage in DNA at a specific wavelength of $254.3 \mathrm{~nm}$ increased absorption and increased the likelihood of microbial death because of the photopolymerization of thymine present in DNA. An increase in DNA damage affects regeneration and functions in microorganisms, resulting in microbial death (Friedberg, 2005; Sinha, 2002). However, ozone is part of the oxidation chemical process and attacks the double bonds present in the proteins and lipids around the structure of the microorganism (Burnett, 2007; Kim 1999).

The decontamination mechanism in biological materials is different for ozone and for UV. Ozone oxidizes proteins, lipids, and fats in the protective layer of cells and does not selectively oxidize the double bonds present in microorganisms (Medeiros, 2010). The sterilization method with UV and ozone presents distinct actions in microorganisms and simultaneously creates a difficult environment for the biological materials present in the plates (Burnett, 2007; Santos et al., 2010). The mechanism of the reaction with ozone plus UV was described by Sidney-Chapman (Burnett, 2007):

Ozone formation:

$$
\begin{gathered}
\mathrm{O}_{2}(\text { atmospheric air })+\mathrm{UV}(\lambda<243 \mathrm{~nm}) \rightarrow 2 \mathrm{O} \text { (free radicals) } \\
\mathrm{O}+\mathrm{O}_{2} \rightarrow \mathrm{O}_{3} \text { (ozone) }
\end{gathered}
$$

Ozone decomposition:

$$
\begin{gathered}
\mathrm{O}_{3}+\mathrm{UV}(240<\lambda<320 \mathrm{~nm}) \rightarrow \mathrm{O}_{2}+\mathrm{O} \\
\mathrm{O}+\mathrm{O}_{3} \rightarrow 2 \mathrm{O}_{2} \text { (Ozone) }
\end{gathered}
$$


Equations 1 and 2 show that for wavelengths between 240 and $320 \mathrm{~nm}$, bonds present on ozone molecules have the capability to be broken, creating a radical oxygen with a high capacity for oxidation. This oxidation can attack several bonds present in molecules in microorganisms, such as those of lipids, proteins, and basic compounds. Cells within microorganisms can have altered primary characteristics (for example, structural changes) because this reaction does not have a selective mechanism (Solomons, 2006; Burnett, 2007; Kim, 1999). This instrumental study demonstrates the possibility of using the same platform for three microbial agents in a single device since the simultaneous use of UV and ozone can decrease the time needed for sterilization, which may be due to the initial UV action, as shown in fig. 3 C. Microorganisms may become more vulnerable to the oxidizing action of ozone (fig. 5 - B), decreasing the sterilization time of the device.

\section{Conclusions}

This study shows that the inactivation of microorganisms in the flat plate test in the UVC protocol requires 30 minutes for sterilization of $10^{6}, 10^{8}, 10^{9} \mathrm{CFU} / \mathrm{mL}$ of the E. coli (ATCC - 25922); however, for $10^{10} \mathrm{CFU} / \mathrm{mL}$, a decrease of $99.9 \%$ of the microorganism was observed in the flat plate. Between 30 and $40 \mathrm{~min}$, microorganism growth was not observed. At this time frame, we determined that the flat plate was sterilized; therefore, this technique has the capability to perform sterilization. Moreover, the other protocol is only applied with ozone under the same conditions and microorganism concentration; however, these results differ from those described above because within 40 min, the entire sample was sterilized at different concentrations, and it is possible to utilize the ozone protocol in the multifunctional autoclave. The last validation process is application of the ozone + UV protocol. Under the same conditions, with the conjugate protocol, the growth of $E$. coli was reduced at almost every concentration tested, although at $10^{10} \mathrm{CFU} / \mathrm{mL}, E$. coli growth was reduced by $99.9 \%$. A sterilization time of $40 \mathrm{~min}$ inactivated the microorganism. The results of this study show that contamination control and the photonic technique results were good with the application of ozone, UV, and ozone/UV.

\section{Acknowledgements}

The authors acknowledge the support provided by: FAPESP (São Paulo Research Foundation)-grant number: 2013/07276-1 (CEPOF-CEPID Program) and Project support by: Bio-Art-grant number: 2014.1.963.76.9(USP/IFSC/FAFQ).

\section{References}

Aguiar, A. M. S. (2006). Avaliação do emprego da radiação ultravioleta na desinfecção de águas com cor e turbidez moderada. 114.

Atlas, R. M., Williams, J. F., \& Mark, K. (1995). Legionella contamination of dental-unit waters. Environ microbiol, 61(4), 1208-1213.

Block, S. S. (2001). Disinfection, sterilization and preservation. Lippincott Willians \& Wilkins.

Burnett, D., Rodriguez, M., SEStak, S., Alton, J., \& Stansbery, E. (2007). Decontamination of genesis array materials by UV Ozone cleaning.

Friedberg, E. C., Walker, G. C., Siede, W., \& Wood, R. D. (2005). DNA repair and mutagenesis. Am Soc Microbiol Press.

Gayán, E., Condón, S., \& Álvarez, I. (2014). Biological aspects in food preservation by ultraviolet light: a review. Food and Bioprocess Tech, 7, 1-20. https://doi.org/10.1007/s11947-013-1168-7

Guzel-Seydim, Z. B., Greene, A. K., \& Seydim, A. (2004). Use of ozone in the food industry. LWT-Food Sci and Tech, 37, 453-460. https://doi.org/10.1016/j.lwt.2003.10.014

Junqueira, L. C. U., Carneiro, J., \& Bustos, E. (1998). Biologia Celular y molecular. Mcgraw-hill interam.

Kim, J. G., Yousef, A. E., \& Dave, S. (1999). Application of ozone for enhancing the microbiological safety and qulity of foods: a review. J Food Protect, 62, 1071-1087. https://doi.org/10.4315/0362-028X-62.9.1071

Medeiros, R. C. (2010). Comparação da resistência de protozoários patogênicos Giardispp. E Cryptosporidium spp. De microrganismos indicadores à desinfecção sequencial cloro-radiação ultravioleta e ozônio-radiação ultravioleta. Univ São Paulo, 210.

Santos, E. R., Correia, F. C., Wang, S. H., Hidalgo, P., Fonseca, F. J., Júnior, E. C. B., \& Andrade, A. M. (2010). Reator de UV-Ozônio com lâmpada a vapor de mercúrio a alta pressão modificada para tratamento superficial de óxidos transparentes condutivos utilizados em dispositivos poliméricos eletroluminescentes. Quim Nova, 33, 1779-1783. https://doi.org/10.1590/S0100-40422010000800027 
Sinha, R. P., \& Haer, D. P. (2002). UV-induced DNA damage and repair: a review. Photoch \& Photobiol Sci, 1, 225. https://doi.org/10.1039/b201230h

Solomons, W., \& Fryhle, C. B. (2006). Quím Org.

Tortora, G. J., Funke, B. R., \& Case, C. L. (2009). Microbiologia. Artmed Editora.

\section{Copyrights}

Copyright for this article is retained by the author(s), with first publication rights granted to the journal.

This is an open-access article distributed under the terms and conditions of the Creative Commons Attribution license (http://creativecommons.org/licenses/by/4.0/). 